\title{
Alternative splicing of arsenic (III oxidation state) methyltransferase
}

\author{
D. Sumi \& S. Himeno \\ Faculty of Pharmaceutical Sciences, Tokushima Bunri University, Tokushima, Japan
}

\begin{abstract}
We identified two splicing variants of the human arsenic (III oxidation state) methyltransferase (AS3MT) gene in HepG2 cells. One splicing variant was an exon-3 skipping $(\Delta 3)$ form which produced a premature stop codon, and the other was an exon-4 and -5 skipping $(\Delta 4,5)$ form which produced a $31.1 \mathrm{kDa}$ AS3MT protein, lack of methyltransferase activity. In addition, we found that exposure of HepG2 cells to hydrogen peroxide ( $\mathrm{H} 2 \mathrm{O} 2)$ resulted in increased levels of a novel spliced form skipping exon-3 to exon- 10 ( $\Delta 3-$ 10). These data suggest that abnormal alternative splicing of AS3MT mRNA may affect arsenic methylation ability and the splicing of AS3MT pre-mRNA was disconcerted by oxidative stress.
\end{abstract}

\section{INTRODUCTION}

In mammals, arsenic (III oxidation state) methyltransferase (AS3MT) catalyzes the formation of monomethylarsonate $(\mathrm{MMA}(\mathrm{V}))$ and dimethylarsinic $\operatorname{acid}(\mathrm{DMA}(\mathrm{V}))$ from arsenite (As(III)) and monomethylarsonous acid (MMA(III)), respectively, as a substrate. When exposed to As(III) contained in the diet or drinking water, AS3MT knockout mice showed high systemic toxicity in the bladder epithelium, mild acute inflammation in the liver, and hydronephrosis in the kidneys, and the incidences of these tissue damages in AS3MT knockout mice were higher than those in WT mice. Although these reports indicate that AS3MT activity plays an important role in the modulation of arsenic toxicity, little is known about the mechanisms underlying the regulation of AS3MT activity and of AS3MT gene expression (Sumi et al., 2011).

Alternative splicing generates more than two mRNAs by alteration in the location and combination at the splicing sites, resulting in variant isoforms of the protein translated from a single gene. Environmental chemicals that are known to cause oxidative stress, such as paraquat and arsenic, were shown to impair control over mRNA splicing, resulting in the deregulation of the survival of motor neurons (SMN) and the induction of DNA damage in gene $45 \alpha$ (GADD45 $\alpha$ ). It has been reported that hydrogen peroxide $\left(\mathrm{H}_{2} \mathrm{O}_{2}\right)$ stimulates alternative splicing of hypoxanthine guanine phosphoribosyl transferase (HPRT) and soluble guanylyl cyclase (sGC). Thus, it is apparent that oxidative stress causes splicing abnormalities on specific mRNAs. However, it remains unknown whether the control of splicing of AS3MT mRNA is vulnerable to oxidative stress.

We identified two splicing variants of the human AS3MT gene in human HepG2 cells. One of the two splicing variants of human AS3MT does not have methyltransferase activity. In addition, we found a novel splicing variant of AS3MT mRNA triggered by $\mathrm{H}_{2} \mathrm{O}_{2}$ (Sumi et al., 2016).

\section{METHODS/EXPERIMENTAL}

\subsection{Cell culture}

HepG2 cells were obtained from ATCC and were cultured at $37^{\circ} \mathrm{C}$ in a humidified atmosphere of $5 \% \mathrm{CO}_{2}$ using Dulbecco's modified Eagle's medium containing $10 \%$ fetal calf serum, penicillin $\left(100 \mathrm{U} \mathrm{mL}^{-1}\right)$, and streptomycin $\left(100 \mu \mathrm{g} \mathrm{mL}^{-1}\right)$.

\subsection{Determination of arsenic methylation activity}

The reacted samples and cell lysates suspended in $150 \mathrm{mM}$ Tris- $\mathrm{HNO}_{3}$ were then sonicated and incubated at $70^{\circ} \mathrm{C}$ for $30 \mathrm{~min}$, and $\mathrm{H}_{2} \mathrm{O}_{2}$ was added to a final concentration of $10 \%$ at room temperature for $3 \mathrm{~h}$ for the oxidation of arsenic metabolites. These samples were centrifuged at $15,000 \times \mathrm{g}$ for $10 \mathrm{~min}$ at $4^{\circ} \mathrm{C}$, and the supernatant was applied to an Amicon YM-3 centrifugal filter at $15,000 \times \mathrm{g}$ for $20 \mathrm{~min}$ at $4^{\circ} \mathrm{C}$. The eluate $(5 \mu \mathrm{L})$ was separated by a nanospace HPLC system on a Capcell Pak C18 MGII $(1.0 \mathrm{~mm}$ i.d. $\times 150 \mathrm{~mm}$ long) using $5 \mathrm{mM}$ tetrabutylammonium hydroxide, $3 \mathrm{mM}$ malonic acid, and $4 \%$ methanol, as a mobile phase with a flow rate of $200 \mu \mathrm{L} / \mathrm{min}$. The eluates from the HPLC column were directly introduced into the ICP-MS spray chamber (ICP-MS 7700x).

\section{RESULTS AND DISCUSSION}

\subsection{Splicing variants of human AS3MT mRNA and activity}

When we carried out RT-PCR with total RNA extracted from HepG2 cells and the primers containing the initiation and termination codons of human AS3MT, 


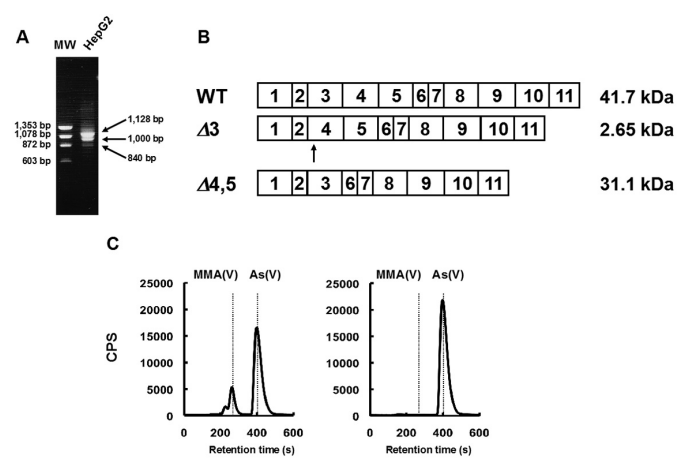

Figure 1. Splicing variants of human AS3MT mRNA and activity. A: RT-PCR was performed in HepG2 cells. B: The diagram of the full-length, $\Delta 3$, and $\Delta 4,5$ splicing variants of AS3MT mRNA. The arrow indicates the site of premature stop codon in $\triangle 3$ AS3MT mRNA. C: Arsenic speciation in samples reacted with recombinant WT or $\Delta 4,5$ AS3MT protein, SAM, GSH and As(III).

we found that three PCR products were amplified (Fig. 1A), suggestive of alternative splicing. Therefore, we determined DNA sequences of the three PCR products following the ligation of each PCR product to the sequencing vector. Results obtained from DNA sequence revealed that $1,128,1,000$, and $840 \mathrm{bp}$ cDNAs represent a full-length (WT) AS3MT mRNA, a splicing variant in which exon-3 is deleted $(\Delta 3$ AS3MT), and a splicing variant in which both exon-4 and -5 are deleted $(\triangle 4,5$ AS3MT), respectively (Fig. 1B). The WT AS3MT protein was calculated to be $41.7 \mathrm{kDa}$ (375 amino acids), while the $\triangle 4,5$ AS3MT protein was $31.1 \mathrm{kDa}$ (279 amino acids). On the other hand, the $\triangle 3$ AS3MT protein was calculated to be $2.65 \mathrm{kDa}$ ( 23 amino acids) due to the appearance of a premature stop codon derived by frame shift (Fig. $1 \mathrm{~B}$, arrow).

In order to investigate whether the product of $\Delta 4,5$ AS3MT mRNA possesses arsenic methyltransferase activity, purified protein was prepared. Arsenic speciation with HPLC-ICP-MS showed a clear peak of MMA(V) after the incubation of As(III) with the recombinant WT AS3MT protein (Fig. 1C, left). However, the peaks of methylated arsenic species were not detected after the incubation with the recombinant $\Delta 4,5$ AS3MT protein (Fig. 1C, right). These results indicate that the $\Delta 4,5$ AS3MT protein lacks arsenic methyltransferase activity.

\subsection{A novel spliced form of human AS3MT mRNA triggered by $\mathrm{H}_{2} \mathrm{O}_{2}$ exposure}

In order to determine whether oxidative stress induces alternative splicing on AS3MT mRNA, total RNA was extracted from $\mathrm{HepG} 2$ cells exposed to $\mathrm{H}_{2} \mathrm{O}_{2}$. We carried out RT-PCR with total RNA using primers, located at exon 2 and exon 11 on AS3MT mRNA, respectively. As shown in Figure 2, the mRNA levels of the spliced form of $\Delta 3$ were not increased by exposure to $\mathrm{H}_{2} \mathrm{O}_{2}$, but rather decreased. However, we detected an increase

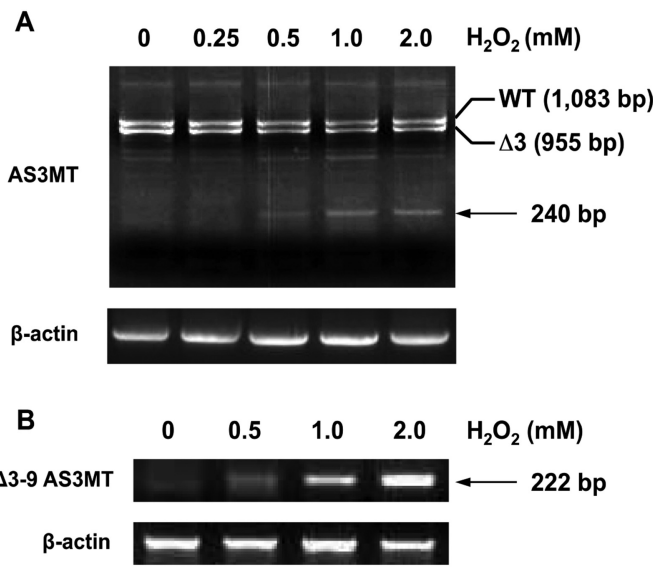

Figure 2. A novel spliced form of human AS3MT mRNA triggered by $\mathrm{H}_{2} \mathrm{O}_{2}$ exposure. HepG2 cells were exposed to indicated concentrations of $\mathrm{H}_{2} \mathrm{O}_{2}$ for $6 \mathrm{~h}$. RT-PCR was performed.

of a novel band at 240 bp in an $\mathrm{H}_{2} \mathrm{O}_{2}$-concentrationdependent manner. DNA sequencing revealed that this band is derived from the AS3MT mRNA skipping the exons from 3 to $9(\Delta 3-9)$. The appearance of the $\Delta 3-9$ splicing variant was confirmed by using the specific primers located at the junction of exons 2 and 10 (Fig. 2B).

\section{CONCLUSIONS}

We found that alternative splicing of AS3MT mRNA in basal condition and splicing abnormalities in AS3MT mRNA were caused by $\mathrm{H}_{2} \mathrm{O}_{2}$, suggesting that the splicing of AS3MT mRNA is vulnerable to oxidative stress. It has been reported that the expression of AS3MT plays an important role in arsenic metabolism and toxicity manifestation among people living in arseniccontaminated areas. Further studies are required to evaluate alternative splicing of the AS3MT gene among different populations and the roles of such splicing in individual differences in the capacity for arsenic methylation.

\section{ACKNOWLEDGEMENTS}

This work was supported by JSPS KAKENHI Grant Number JP26670068.

\section{REFERENCES}

Sumi, D., Fukushima K., Miyataka, H., \& Himeno, S. 2011. Alternative splicing variants of human arsenic $(+3$ oxidation state) methyltransferase. Biochem. Biophys. Res. Commun. 415(1): 48-53.

Sumi, D., Takeda, C., Yasuoka, D., \& Himeno S. 2016. Hydrogen peroxide triggers a novel alternative splicing of arsenic (+3 oxidation state) methyltransferase gene. Biochem. Biophys. Res. Commun. 480(1): 18-22. 